\title{
The Concept of Equilibrium in Different Economic Traditions
}

An Historical Investigation

Bert Tieben

SEO Economic Research, Amsterdam, The Netherlands

\section{Edward Elgar}

Cheltenham, UK • Northhampton, MA, USA 